\title{
Effect of rebreathing on psychomotor skills when wearing integral crash helmets
}

\author{
A. F. MALINS, $*$ J. S. CURNOW, $\dagger$ P. J. F. BASKETT $\ddagger$ AND \\ R. GREENBAUM $\S$ \\ *Department of Anaesthetics, Queen Elizabeth Hospital, Birmingham; †Department of \\ Physics, Bristol Royal Infirmary, Bristol; $\ddagger$ Department of Anaesthetics, Frenchay \\ Hospital, Bristol; §Department of Anaesthetics, University College Hospital, London
}

\section{SUMMARY}

Nine volunteer subjects underwent psychomotor testing when wearing an integral crash helmet in a variety of conditions which lead to rebreathing. There was a wide individual variation in the extent of rebreathing. In the worst conditions the minimum inspired carbon dioxide tension $\left(\mathrm{P}_{\mathrm{I}} \mathrm{CO}_{2}\right)$ increased to $2.6 \mathrm{kPa}$. The psychomotor test was a tracking test based on a microcomputer. There was a significant deterioration in the ability to perform the test when the helmet was worn with the visor down and restricted airflow into the helmet $(P=<0.05)$. In those tests when the minimum $\mathrm{P}_{\mathrm{I}} \mathrm{CO}_{2}$ exceeded $0.5 \mathrm{kPa}$ the decrease in performance was more highly statistically significant $(\mathrm{p}=<0.005)$.

Rebreathing wearing integral crash helmets results in a variable impairment in the subjects' ability to perform a tracking test.

We recommend that the maximum level of $\mathrm{CO}_{2}$ retention inside integral crash helmets should not exceed $0.5 \mathrm{kPa}$ minimum $\mathrm{P}_{\mathrm{I}} \mathrm{CO}_{2}$.

\section{INTRODUCTION}

It has been demonstrated that rebreathing occurred in a subject wearing a variety of integral crash helmets under differing conditions (Greenbaum et al., 1982). Carbon dioxide retention inside integral 'full face' helmets has been confirmed by another study (Aldman et al., 1981). 
In the worst conditions the maximum inspired oxygen can decrease to $16.0 \mathrm{kPa}$ with a concomitant increase in minimum inspired carbon dioxide tension $\left(\mathrm{P}_{\mathrm{I}} \mathrm{CO}_{2}\right)$ to $2 \cdot 1 \mathrm{kPa} \frac{\mathrm{D}}{\mathrm{D}}$ (Greenbaum et al., 1982).

At altitude with minor degrees of hypoxia causing hyperventilation and hypocapnia? there is interference with visual discrimination, night vision and a worsening of psychomotor performance (Cotes, 1979; Guyton, 1979). If these or similar effects occur with individuals wearing integral helmets then recommendations may be required to듬 limit the extent of rebreathing.

\section{METHODS}

Nine male volunteer subjects were recruited, five regularly wore crash helmets, four did not. They were physically fit and not receiving any medication. Each acted as his own? control.

Psychomotor skills were assessed using a two dimensional compensatory tracking $\vec{\circ}$ test, an established test of psychomotor performance (Hammerton, 1981). This was based on a microcomputer which generated a target and a cross in the centre of $a_{-}^{\mathrm{S}}$ television monitor. The cross randomly moved away from the centre of the target and $\bar{c}$ the task was to keep the cross in the centre by means of a hand held joystick. Every $30 \mathrm{~ms}$ the distance of the cross from the centre was calculated by the computer. Each $\overrightarrow{0}$ test period lasted $3 \mathrm{~min}$ and the results from the first $30 \mathrm{~s}$ disregarded. The score w\$s! recorded as the root mean squared distance (units). A maximum deflection from the centre of the target to the edge of the monitor screen was 110 units.

Prior to the day of testing each subject was allowed a period of practice. Each session began with a further practice period of up to $30 \mathrm{~min}$ to establish stability and a control $\frac{\mathrm{O}}{\mathrm{Q}}$ score. The last 3 practice scores were used to calculate a mean control score.

The tests were performed in the same well lit room between $2.00-6.00 \mathrm{pm}$ with the subject positioned $1 \mathrm{~m}$ from the monitor.

Minimum inspired $\mathrm{CO}_{2}\left(\mathrm{P}_{1} \mathrm{CO}_{2}\right)$ was measured with a Gould Godart Capnograph. The sampling was made via a tube taped to the subjects upper lip to permit breath by breath analysis of respired air. The mean minimum $\mathrm{P}_{1} \mathrm{CO}_{2}$ was calculated as a mean of 20 consecutive breaths under steady state conditions.

The test conditions with the helmet with a clear scratch-free visor worn were-(A) visor open; (B) visor closed; (C) visor closed with balaclava and scarf. The last condition $₹$ attempted to maximize the extent of rebreathing by reducing airflow into the helmet. $ᄋ$ Each subject was randomly allocated to one of six sequence conditions $(A, B, C ; B, A, C ; D$ $\mathrm{C}, \mathrm{B}, \mathrm{A}$, etc.). Tests were performed in static conditions i.e. no airflow over the helmet.

The results were analysed using ' $t$ ' tests for paired data.

\section{RESULTS}

Rebreathing occurred in all subjects when wearing a crash helmet with the visor closed $\stackrel{\oplus}{\rightarrow}$ with or without the balaclava and scarf (Table 1). The minimum $\mathrm{P}_{\mathrm{I}} \mathrm{CO}_{2}$ varied widely 
between individuals (range $0 \cdot 15 \mathrm{kPa}$ to $2 \cdot 6 \mathrm{kPa}$ ). Under these circumstances there was a significant deterioration in the subjects ability to perform the tracking test in conditions $B$ and $C(p=<0.05)$ as compared with control scores. Impairment of the subjects' ability to keep the cross in the centre of the target results in a higher score. When the minimum $\mathrm{P}_{\mathrm{I}} \mathrm{CO}_{2}$ exceeded $0.5 \mathrm{kPa}$ (Table 2) $\mathrm{t}$ here was a greater impairment of psychomotor performance $(\mathrm{p}=<0 \cdot 005)$.

Table 1 The effect of wearing an integral crash helmet on mean tracking scores

\begin{tabular}{|c|c|c|c|}
\hline Condition & \multirow{2}{*}{$\frac{\text { Score }}{19.95(3.5)}$} & \multicolumn{2}{|c|}{$\mathrm{P}_{1} \mathrm{CO}_{2}$ range $\mathrm{kPa}(\mathrm{mm} \mathrm{Hg})$} \\
\hline Control & & \multicolumn{2}{|c|}{$<0 \cdot 1$} \\
\hline \multicolumn{4}{|l|}{ Helmet on } \\
\hline A Visor open & $20 \cdot 8(2 \cdot 9)$ & $0 \cdot 07-0 \cdot 16$ & $(0 \cdot 5-1 \cdot 2)$ \\
\hline B Visor closed & $22 \cdot 1(3 \cdot 0)^{*}$ & $0 \cdot 15-1 \cdot 17$ & $(1 \cdot 1-8 \cdot 8)$ \\
\hline C Visor closed with balaclava and scarf & $22 \cdot 7(3.8)^{*}$ & $0 \cdot 8-2 \cdot 6$ & $(6 \cdot 0-19 \cdot 5)$ \\
\hline
\end{tabular}

Mean tracking test scores $( \pm \mathrm{SD})$ and minimum $\mathrm{P}_{1} \mathrm{CO}_{2} \mathrm{kPa}(\mathrm{mm} \mathrm{Hg}) \mathrm{n}=9$

* statistical significance $p=<0.05$ as compared with controls conversion factor $1 \mathrm{kPa}=7.5 \mathrm{~mm} \mathrm{Hg}$

Table 2 Mean tracking test scores $( \pm \mathrm{SD})$ and mean minimum inspired carbon dioxide tensions $\left(\mathrm{P}_{1} \mathrm{CO}_{2}\right)$ in $\mathrm{kPa}(\mathrm{mmHg})$

\begin{tabular}{lcc}
\hline $\mathrm{P}_{1} \mathrm{CO}_{2}$ (range) & Test score & Control score \\
\hline $0-0.5 \mathrm{kPa}$ & $21.2(3.0)$ & $20.4(3.6)$ \\
$(0-3.75 \mathrm{mmHg})$ & $\mathrm{n}=10$ & \\
$0.5-2.6 \mathrm{kPa}$ & $22.0(3.5)^{*}$ & $19.7(3.4)$ \\
$(3.75-19.5 \mathrm{mmHg})$ & $\mathrm{n}=17$ & \\
\hline
\end{tabular}

* statistical significance $p=<0.005$ as compared with controls

\section{DISCUSSION}

Rebreathing occurs when wearing integral crash helmets. This study demonstrates an associated decrease in psychomotor skills as assessed using a tracking test. A similar study (Aldman et al., 1981) revealed no impairment of psychomotor performance when breathing $0 \%, 3 \%, 5 \% \mathrm{CO}_{2}$ in air. However, the study did not take into account the hypoxia which results from rebreathing.

The extent of rebreathing did vary between individuals and this may be as a result of; differing head and neck morphology; the variation in respiratory patterns; the seal around the base of the helmet-all affecting the inflow of fresh air.

Our results should not be interpreted as condemning the use of crash helmets. The incidence of head injuries in Kansas rose by $70 \%$ when the law requiring compulsory wearing of helmets was repealed. The mortality in those not wearing crash helmets was increased threefold. 
With the impairment of tracking test performance when the minimum $\mathrm{P}_{1} \mathrm{CO}_{2}$ exceeds $0.5 \mathrm{kPa}(0.5 \%)$ we recommend this level of carbon dioxide retention as a limit. On the road there will be airflow over the helmet which will reduce rebreathing. However, in $\frac{3}{\infty}$ certain circumstances this limit may be exceeded when the rider restricts airflow into his helmet (Greenbaum et al., 1982; Aldman et al., 1981).

Although the previously quoted study (Aldman et al., 1981) showed no impairment of psychomotor performance the authors recommended a similar limit to $\mathrm{CO}_{2}$ retention inside integral crash helmets.

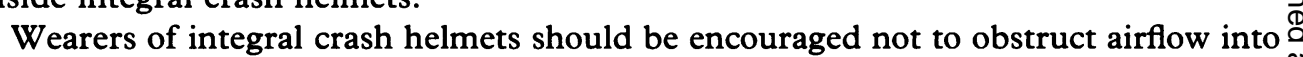

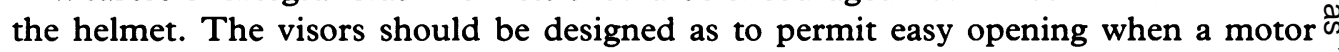
cyclist stops.

We believe that the impairment of psychomotor performance may adversely affect a $\vec{\omega}$ motorcyclists ability to control his machine although other factors may be involved. $\frac{\circ}{\circ}$ Rebreathing could be eliminated by minor modifications to helmet design with the $\frac{\mathbb{D}}{3}$. instruction not to obstruct airflow into the helmet.

\section{ACKNOWLEDGEMENTS}

We thank Dr E. Farmer, RAF Institute of Aviation Medicine for his assistance with the psychomotor testing programme and Ms Lynne Breeze for preparing the manuscript.

\section{REFERENCES}

Aldman B., Balldin U., Gustafsson H., Nygren A., Sporrong A. \& Strand I. (1981) Carbon dioxide retention inside motor-cycle helmets. In Proceedings VIth IRCOBI Conference, Salon-de-Provence, France.

Cotes J. E. (1979) Lung Function 4E, p 468. Oxford, Blackwell Scientific Publications Ltd.

Greenbaum R., Malins A. F., Davies R. \& Baskett P. J. F. (1982) Rebreathing in a subject wearing an integral crash helmet. British Medical fournal 284, 774.

Guyton A. C. (1979) Textbook of medical physiology, p 588 Philadelphia, W. B. Saunders.

Hammerton M. (1981) Tracking In Human Skills, p 177 (D. Holding (ed.)) John Wiley and Sons. 